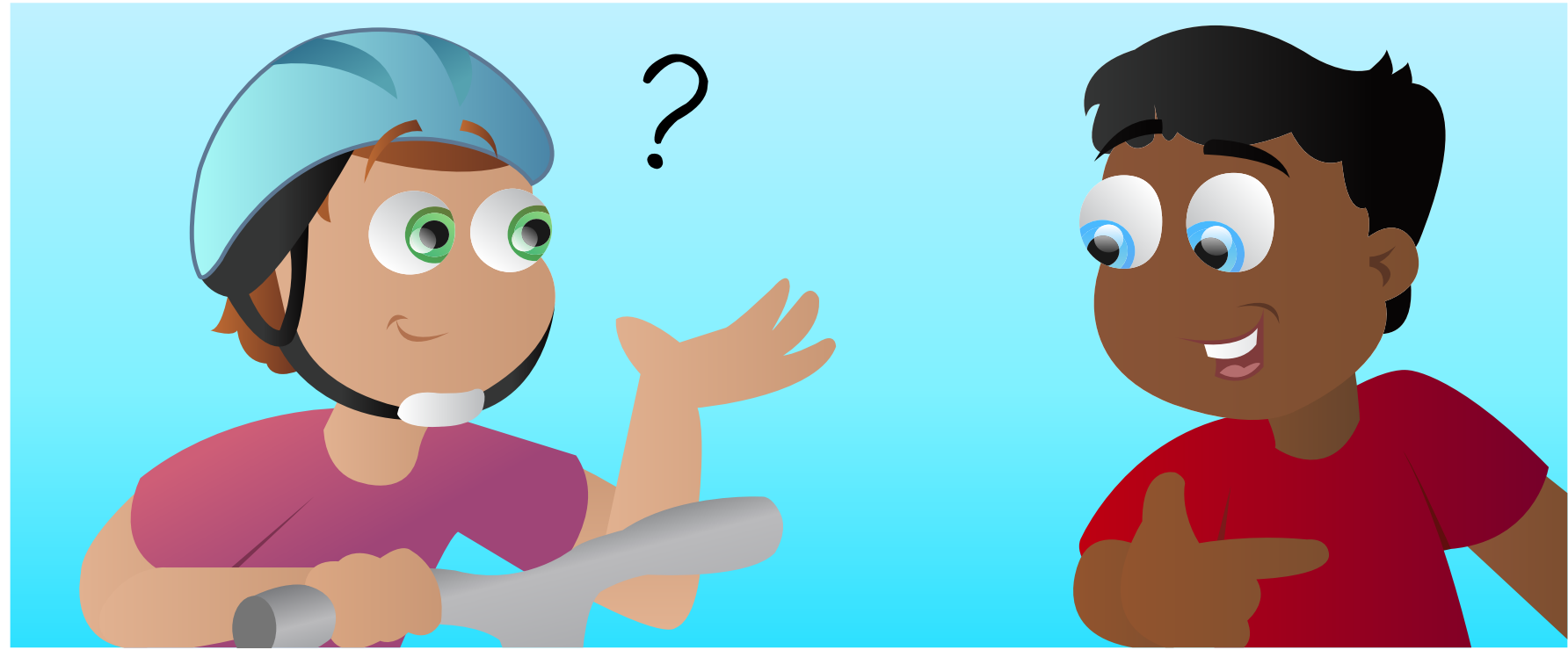

\title{
HUMAN COMMUNICATION AND THE BRAIN
}

\section{Arjen Stolk*}

Helen Wills Neuroscience Institute, University of California, Berkeley, Berkeley, CA, USA

\section{REVIEWED BY: \\ KRISHNA \\ 11 YEARS OLD \\ DARIUS \\ 13 YEARS OLD

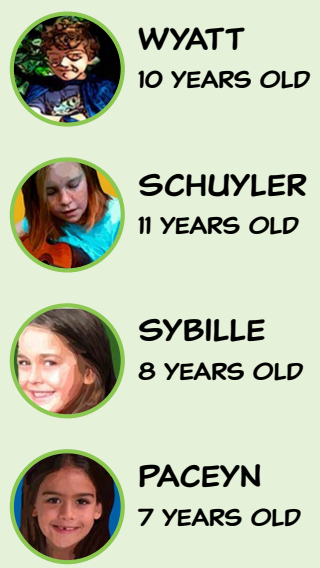

If a person on the street asks you for directions to the movie theater, the person's age or the presence of a bike instead of a car is just one of the multiple contextual elements that will influence your reply. You may decide to speak more clearly, use simpler words, or give directions specifically on how to get there by bike. Yet, despite the ease with which we flexibly adjust our communication according to the person we are communicating with, it remains a mystery how we manage to rapidly do that. A new study shows that a certain part of our brain, called the prefrontal cortex, is particularly important for fine-tuning communication depending on the person we are communicating with. Patients with damage to the prefrontal cortex are still able to communicate. Unlike healthy individuals and patients with brain damage elsewhere, however, prefrontal patients fail to adjust their communication to the abilities of the person with whom they are communicating.

Phineas Gage was a railroad construction worker in the 1800 s who was involved in a horrible accident. While at work, an explosion propelled an inch thick iron rod completely through his forehead, as illustrated in Figure 1. You might think this accident would leave him seriously injured or, even worse, dead! But no, despite destroying parts of the front of his brain, this terrible event had very little effect on him, surprisingly [1,2]. Phineas Gage regained full consciousness immediately after the accident. And despite 
FIGURE

Phineas Gage, holding the iron rod that penetrated his forehead.

\section{PREFRONTAL}

\section{CORTEX}

A brain region right above your eyes and implicated in guiding complex behavior.

\section{COMMUNICATION}

The act of conveying a thought or idea from one person to another.

\section{BRAIN DAMAGE}

A destruction of brain cells that disrupts the brain region's normal functioning. Brain damage can occur due to external force (trauma), internal force such as in the case of pressure from a tumor, or neurological illness.
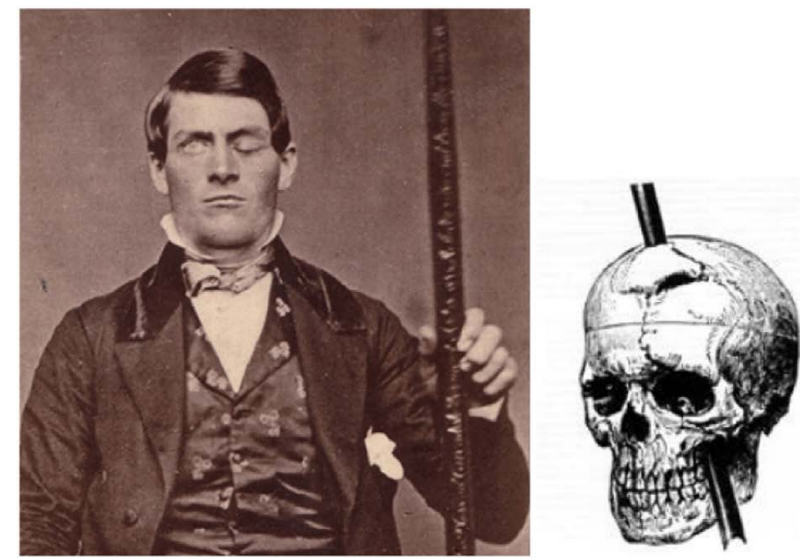

FIGURE 1

having a gaping hole in his forehead, he was still able to walk and talk, and he continued to live for almost 12 more years. Could this surprising observation mean that the prefrontal cortex, the brain area right above our eyes, is simply not important for daily functioning? Or, does the prefrontal cortex have other functions that we still don't understand? Unfortunately, there isn't a lot of evidence to give us clues about whether the accident changed Phineas Gage's behavior. We know that, for unknown reasons, the railroad company refused to rehire him after the accident. Furthermore, the few stories that do exist about Phineas Gage's behavior after the accident suggest that his personality and attitude toward others changed in some way, with friends saying that Gage was "no longer Gage."

Neuroscience (the science that studies how the brain functions) continues to teach us new things about the role of the prefrontal cortex in our everyday lives. Ask yourself: would you tell a complete stranger the same personal things you tell your family and friends, such as a treasured memory? Scientists found that patients with serious injury to the prefrontal cortex did tell strangers these personal things, even though they felt embarrassed about it afterward [3]. But, why didn't the patients take into account that they were talking to a stranger? Could it be that the prefrontal cortex is necessary for adjusting our communication based on the person we are communicating with?

\section{USING A COMPUTER GAME TO INVESTIGATE COMMUNICATION}

How can we investigate whether the prefrontal cortex is necessary for adjusting our communication (how we talk to others and the types of things we tell them) depending on the person we are communicating with? One way to find an answer to this question is to actually measure the way people adjust their communication when they communicate with different kinds of people, and then to see whether people with prefrontal brain damage (a destruction of brain cells in the prefrontal cortex, called prefrontal patients 


\section{FIGURE 2}

Communication game and the two made-up partners. The goal of the game is for the participant to explain to his partner where to collect the acorn from the digital game board. In this particular instance, the acorn is located on one of the white circles in the bottom center square. By touching the squares on the screen with his/her finger, the participant can move the bird token around on the game board, beginning and ending each turn at the bird's nest in the center.

The bird can only move to the center of each of the nine squares and only through vertical or horizontal movements (see Movie S1). The partner can see the bird movements, and use a computer mouse to move his squirrel to the circle on the game board where he thinks the acorn is located, based on what the participant is telling him using the bird. The participants were told that they would take turns playing the game with an adult and with a 5-yearold child. In reality, there was only one person playing both partners, and that person did not know whether the participant thought he was the child or the adult. This helped us to make sure that that any differences we saw in the participant's

communication were due to the type of person the participant believed he was communicating with, instead of from different performances by the two partners.

\section{MOVIE S1}

Communication behaviors of a prefrontal patient. here, for short) do this differently than people with normal brains. In order to measure changes in communication, we designed a computer game in which the participants used a bird token to communicate with another person through a computer screen, without being able to actually see or talk to that partner. This "online" form of communication has two advantages for our experiment. First, the movements of the bird on the computer screen allow accurate measurement of each participant's communication behaviors. That gives us a way to determine whether those behaviors are adjusted depending on whom the participant is communicating with. Second, the fact that the participants cannot see or hear their partner lets us tell the participants that they will take turns playing with two different partners while there actually is only one! That way, we can make sure that the "two partners" behave in the same way, allowing us to be certain that any differences we see in the way the participants communicate come only from differences in whom they believe they are communicating with.

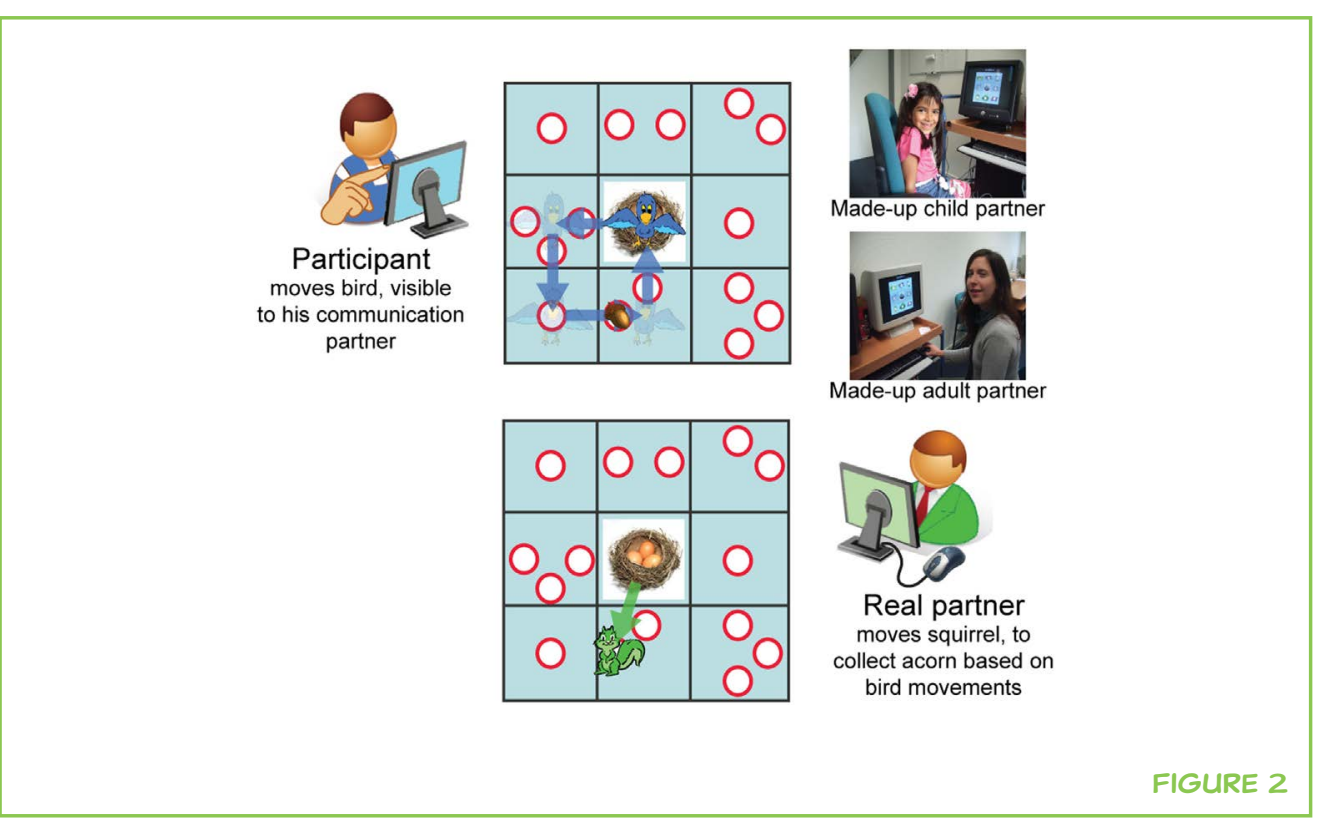

MOVIE SI 


\section{FIGURE 3}

Overlap map for patients with prefrontal brain damage. The image on the left is a view of the brain from the left side of the head. The color bar in the left bottom indicates how many individuals have brain damage to the prefrontal cortex (marked with the white box), around the same area where Phineas Gage suffered injury from an inch thick iron rod. The white horizontal lines correspond to the horizontal cross-sections of the brain shown on the right. These horizontal cross-sections show the brain from above instead from the left. It can be seen that the prefrontal cortex is located right above the eyes.
The communication game is shown in Figure 2. The goal of this computer game is for the participant to explain to a partner where an acorn is located on the game board. The acorn could be on any of the white circles. The participant can "explain" where the acorn is by moving the bird token around on the game board. The partner can see the participant's bird movements on his own separate screen in real time and can then move the squirrel to the circle where he thinks the participant is trying to tell him the acorn is hidden. When the partner makes his choice, both players receive feedback about whether they have successfully communicated and found the location of the acorn.

The participants were informed they would be playing the communication game with two different partners, a child and an adult, who would be sitting in a separate room with their own computer screens. In reality, the participants interacted with one person, who was working with the researchers. That partner did not know whether the participant thought he was playing against the child or the adult, so that we could make sure that the partner's behaviors were the same in either case. An earlier study using this game showed that a participant's beliefs about the age and abilities of their partner may change the way they communicate with their partner. In that study, 5-year-old children paused with the bird over the acorn's location for a longer period of time when they believed they were communicating with a 2 -year-old toddler than when they believed they were communicating with someone their own age [4]. We make these adjustments in communication in our everyday lives, too! Have you ever noticed yourself speaking slower or may be using simpler words when communicating with someone much younger than you?

In our study, we investigated whether prefrontal patients would also be able to change the way they communicated with partners whom they thought were of different ages. The amount of brain damage in these patients can be seen in Figure 3, where the color-coding indicates how many individu-

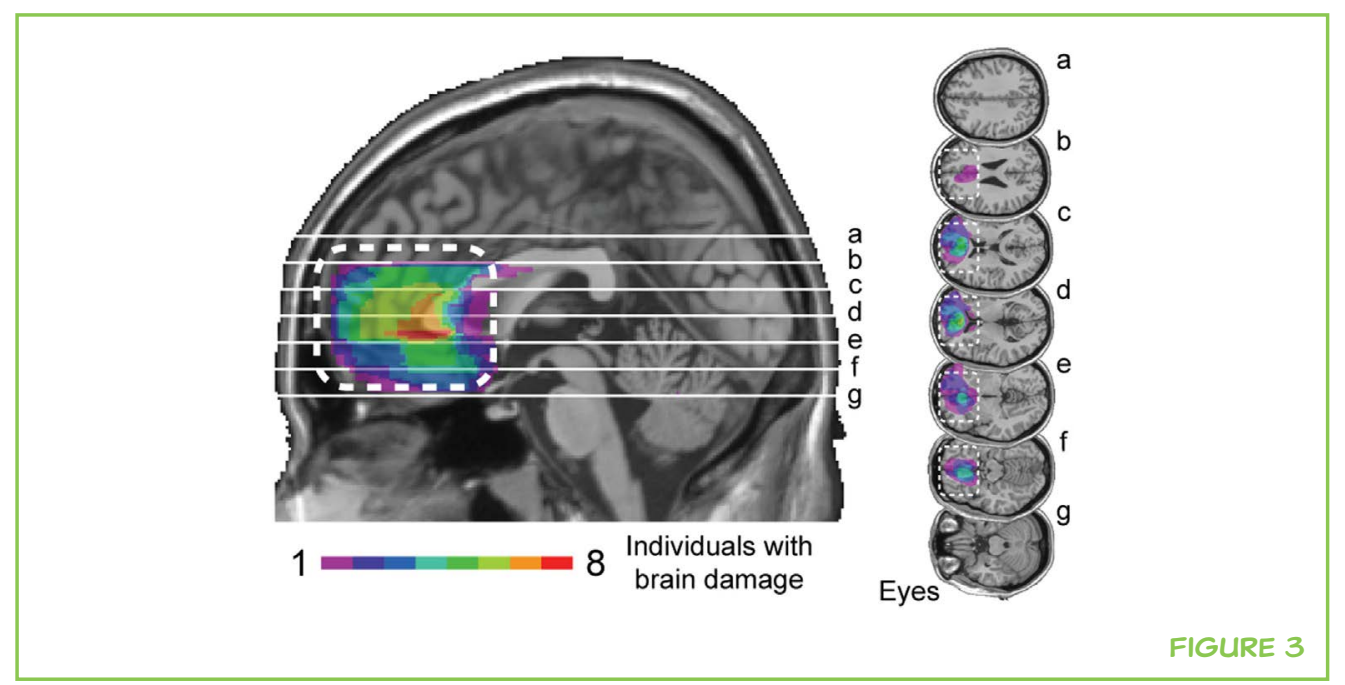


FIGURE 4

Communication adjustments made by the three participant groups. In this graph, the difference in the time spent with the bird token on the location of the acorn during game play is shown separately for each participant group (prefrontal patients, lesion controls, and healthy controls). The pink bars show the participant groups that spent longer (in percentage) with the bird on the location where the acorn was located when interacting with the made-up child than with the made-up adult partner. This shows us that individuals with damage to the prefrontal cortex communicate differently than the other two groups. Note that it seems as if the prefrontal group made adjustments in the reverse direction.

This reverse adjustment, however, was not strong enough to be considered a real effect. als have brain damage to the prefrontal cortex. To make sure that any changes we see in communication are specific to prefrontal brain damage, we compared the communication behavior of the prefrontal patients with the behavior of patients who had damage somewhere else in the brain (we called these "lesion controls," and they had damage to parts of the brain, called the temporal, occipital, or parietal areas). We also compared prefrontal patients' behavior with the behavior of individuals without brain damage (called "healthy controls").

\section{PREFRONTAL PATIENTS COMMUNICATE DIFFERENTLY}

The prefrontal patients could communicate the location of the acorn to their partners just as well as could healthy controls. For example, see Movie S1 in which a patient with prefrontal brain damage manages to communicate to his partner where the acorn is located. Note that this patient spends longer with the bird on the location of the acorn than on any other location on the game board, just as a healthy person would do to put emphasis on that location for their partner. All three groups-prefrontal patients, lesion controls, and healthy controls - had this same behavior. But, we observed an important difference between the communication behaviors of the prefrontal patients and the behaviors of the other two groups. As you can see in Figure 4, the lesion and healthy controls spent more time hovering over the location of the acorn when they believed they were communicating with a child than they did when they thought they were communicating with an adult partner. This difference in the amount of time spent hovering over the circle with the acorn was not observed in the prefrontal patients-they did not spend longer hovering over that location when communicating with the child as compared with the adult partner.

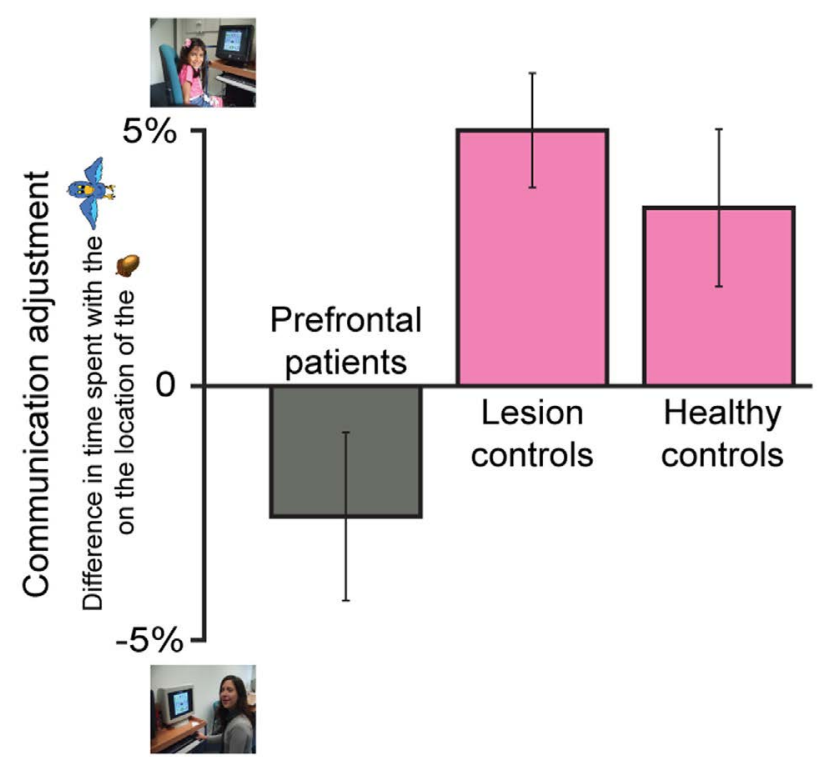

FIGURE 4 
Taken together, our findings told us that our prediction was correct-individuals with prefrontal brain damage no longer adjust their communication according to the person they are communicating with. Interestingly, damage to the prefrontal region does not at all impair the ability or motivation to communicate, as people used to think. Prefrontal patients still communicate effectively, and they actually also spent longer, hovering over the important circles on the game board. However, they did so whether they thought they were communicating with another child or with an adult, while the control groups fine-tuned their communication depending on whether they thought they were communicating with a child or an adult. These results tell us that the prefrontal cortex is not necessary for communication itself, as we saw in the case of Phineas Gage. At the same time, the results explain why individuals with prefrontal brain damage may show socially awkward behavior in everyday life, such as telling a stranger the type of personal information you would normally only share with family and friends [3]. So, the next time you are communicating with someone, remember that you are using the prefrontal cortex, the brain region right above your eyes, to adjust your communication to that person.

\section{ETHICS STATEMENT}

All participants gave informed consent according to the Declaration of Helsinki and the Ethical Committee of the Department of Psychology, University of Bologna.

\section{ACKNOWLEDGMENTS}

I thank my colleagues Julia Kam and Anat Perry and editors Nina Dronkers and Bob Knight for helpful comments on this article. The research leading to these results has received funding from the Netherlands Organization for Scientific Research.

\section{ORIGINAL SOURCE ARTICLE}

Stolk, A., D’Imperio, D., di Pellegrino, G., Toni, I. 2015. Altered communicative decisions following ventromedial prefrontal lesions. Curr. Biol. Available at: http://www. cell.com/current-biology/abstract/S0960-9822(15)00410-8

\section{REFERENCES}

1. Damasio, H., Grabowski, T., Frank, R., Galaburda, A. M., and Damasio, A. R. 1994. The return of Phineas Gage: clues about the brain from the skull of a famous patient. Science 264:1102-5. doi:10.1126/science.8178168

2. Van Horn, J. D., Irimia, A., Torgerson, C. M., Chambers, M. C., Kikinis, R., and Toga, A. W. 2012. Mapping connectivity damage in the case of Phineas Gage. PLoS ONE 7:e37454. doi: 10.1371/journal.pone.0037454 
3. Beer, J. S., John, O. P., Scabini, D., and Knight, R. T. 2006. Orbitofrontal cortex and social behavior: integrating self-monitoring and emotion-cognition interactions. J. Cogn. Neurosci. 18:871-9. doi:10.1162/jocn.2006.18.6.871

4. Stolk, A., Hunnius, S., Bekkering, H., and Toni, I. 2013. Early social experience predicts referential communicative adjustments in five-year-old children. PLOS ONE 8:e72667. doi:10.1371/journal.pone.0072667

SUBMITTED: 05 November 2015; ACCEPTED: 04 April 2017; PUBLISHED ONLINE: 08 May 2017.

EDITED BY: Robert T. Knight, University of California, Berkeley, USA

CITATION: Stolk A (2017) Human Communication and the Brain. Front. Young Minds 5:12. doi:10.3389/frym.2017.00012

CONFLICT OF INTEREST STATEMENT: The authors declare that the research was conducted in the absence of any commercial or financial relationships that could be construed as a potential conflict of interest.

COPYRIGHT @ 2017 Stolk. This is an open-access article distributed under the terms of the Creative Commons Attribution License (CC BY). The use, distribution or reproduction in other forums is permitted, provided the original author(s) or licensor are credited and that the original publication in this journal is cited, in accordance with accepted academic practice. No use, distribution or reproduction is permitted which does not comply with these terms.

\section{REVIEWED BY}

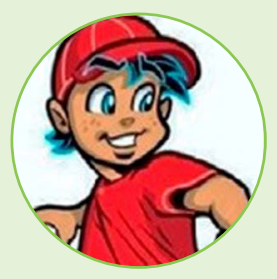

\section{KRISHNA, $\|$ YEARS OLD}

Age 11, sixth grade. I love science and sports. I play baseball and learn kung-fu. I love to do experiments to understand how science works. In science-I enjoy space/astronomy and physics. I enjoy reading a lot and hope to write lot of kids' books (I have started on three already). In my life, I want to invent something new and bring back to life something that is extinct-using DNA research.

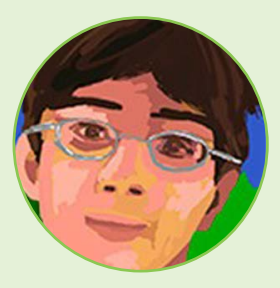

\section{DARIUS, 13 YEARS OLD}

Age 13, eighth grade. I am 13 years old and in the eighth grade. In my free time, I enjoy reading, backpacking, and playing the trumpet and piano. I am passionate about the environment and community service. I am very interested in public speaking and am on my school's debate team. I enjoy learning about science, particularly neuroscience, chemistry, biology, and physics.

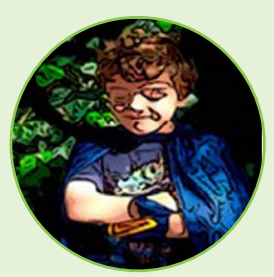

\section{WYATT, 10 YEARS OLD}

Age 10, fifth grade. I am a fifth grader in Piedmont, CA, USA. I like to read, play with Legos, play Minecraft, and eat and sleep! I also love scootering, biking, hiking, and building stuff. My favorite food is Ethiopian - I love the whole fried fish and the doro tibs. My favorite subjects in school right now are computer lab, P.E., library, and science. I am looking forward to taking chemistry when I get to middle school! After college, I want to be a mechanical engineer and robotics programmer. 


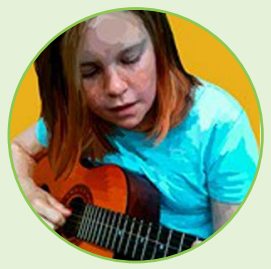

\section{SCHUYLER, $\|$ YEARS OLD}

Age 11, seventh grade. I am Schuyler. I live in Berkeley, CA, USA, I am 11 years old and in the seventh grade. My favorite subjects in school are writing and science. I like to write fictional pieces, and I also like to sing, act, and cook. Someone that I look up to and that inspires me is my mom. I also play soccer and basketball.

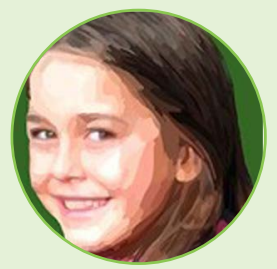

\section{SYBILLE, 8 YEARS OLD}

Age 8, fourth grade. I am Sybille. I am 8 years old and I am in fourth grade at Malcolm X. I live in Berkeley, CA, USA, and I play soccer. I like doing silly science experiments and cooking, and I am really good at math.

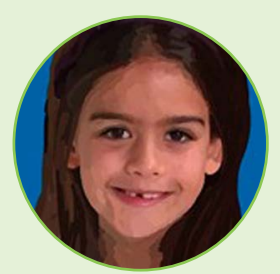

\section{PACEYN, 7 YEARS OLD}

Age 7, second grade. I am Paceyn. I am 7 years old, and I am in second grade at LeConte Elementary in the TWI Spanish program. My favorite subjects in school are reading, writing, and math. I like doing science experiments, making arts, and writing stories, especially poems and songs. I collect rocks and stuffed animals, and I like skiing and cold weather. I enjoy doing gymnastics, dance, and cheersport, and I have a pet guinea pig named Luna.

\section{AUTHOR}

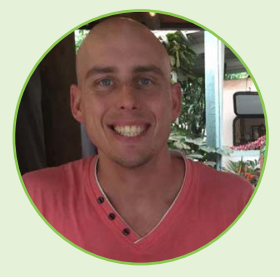

\section{ARJEN STOLK}

We communicate our thoughts and ideas to others all day every day, but we do not understand how. Language certainly helps. However, language is not necessary for communication, as we also understand tourists who speak a different language. My research therefore focuses on how people understand one another in interactive game settings, without language. Besides neuroscience, I enjoy motorcycles, nature, and wild life. *a.stolk8@gmail.com 